\title{
Integrated anti-terrorism physics-based modelling part 2: understanding injuries caused by terrorist attacks in an urban environment
}

\author{
L. A. Young, F. A. Maestas \& J. L. Smith \\ Applied Research Associates, Inc., USA
}

\begin{abstract}
Bombs are increasingly being used by insurgents and terrorists worldwide against both civilian and military targets. Explosives are inexpensive, require little training to deploy, are made from easily obtained materials and serve as an effective means of causing mass casualties. Between 1988 and 1997, the number of criminal bombings in the United States doubled from the previous decade to a total of 17,579, or 5 bombings per day. According to the Department of State, in 2003, 208 terror attacks were perpetrated worldwide, leading to 4,271 casualties. In 2005, the attacks increased to 11,111 attacks, resulting in 39,307 casualties, with the majority of terrorist attacks executed using bombs. The US Department of State's record of worldwide significant terrorist events reveals a dramatic increase in US homeland attacks beginning after 2001, and a review of the last twelve months in Iraq, Israel, London, Pakistan, India and Egypt shows that improvised explosive devices remain the weapon of choice for today's terrorists. To design mitigation and response strategies and to make appropriate medical responses to a terrorist attack, physical security personnel must understand the quantity, nature and severity of injuries that will be caused by direct blast effects, structural debris and building collapse. The purpose of this paper is to provide a survey of existing methodologies for predicting and quantifying blast "bio-effects" and make recommendations for addressing existing shortfalls.

Keywords: survivability, blast injuries, mitigation, physical security, modelling, simulation.
\end{abstract}




\section{Introduction}

In recent decades, improvised explosive devices (IEDs) have been increasingly the preferred means of terrorists to achieve their objectives. The increased use of both conventional and thermobaric weapons is motivating new and innovative efforts within research, development, and medical communities to offer near and long-term improvements in protective gear, in-field diagnostics, therapeutics and rehabilitation. To support these efforts, the blast injury modelling and simulation community must overcome significant technical challenges to providing the required predictive-quality modelling. Although considerable research has been performed in the areas of primary fragment penetration and primary blast overpressure injuries to the ears and lungs, additional research and development injury criteria, engineering models, and numerical models are needed. Furthermore, additional work is needed to quantify the implications of multi-site and multi-aetiology blast wounds with respect to morbidity, mortality and incapacitation.

The development of the required models, simulation tools, and injury criteria requires a multi-disciplinary approach, bringing together both the medical and the engineering communities. This paper presents an overview of the current capabilities and shortfalls with respect to modelling the effects of blast on the human body.

\section{Survey of explosion effects}

The term explosive is generally used to describe energetic materials that react chemically to produce a detonation - a chemical reaction in which the reaction front advances into the un-reacted material at or greater than the sonic velocity of that material. The propagation of a chemical reaction in which the reaction front advances into the un-reacted material rapidly, but at less than the sonic velocity of that material, is referred to as deflagration.

Table 1 summarizes the official US Department of Defense (Directive 6025.21E) nomenclature used to describe the variety of blast effects on personnel.

\section{Capabilities and shortfalls survey}

\subsection{Overview}

Over the past few years, engineering and medical experts from throughout the US Department of Defense have met repeatedly in an effort to develop a concise, coherent assessment of where we stand scientifically and technologically with respect to understanding, predicting, preventing and treating explosion-induced injuries. The results of these meetings are remarkably consistent, with the repeated identification of the following major impediments to mitigating and treating the effects of IED attacks (fig. 1): Epidemiological Data, Validated Injury Criteria, and Physical, Engineering and Numerical Models (Young et al [1]). 
Table 1: Blast injury terminology.

\begin{tabular}{|l|l|}
\hline \multicolumn{1}{|c|}{$\begin{array}{c}\text { Type of } \\
\text { Injury }\end{array}$} & \multicolumn{1}{c|}{ Definition } \\
\hline $\begin{array}{l}\text { Primary } \\
\text { Blast } \\
\text { Injuries }\end{array}$ & $\begin{array}{l}\text { Blast overpressure injury resulting in direct tissue damage from the shock } \\
\text { wave coupling into the body. Major regions typically identified with } \\
\text { primary blast injuries are the ears, lungs and, most recently, the brain. }\end{array}$ \\
\hline $\begin{array}{l}\text { Secondary } \\
\text { Blast }\end{array}$ & $\begin{array}{l}\text { Injury produced by primary fragments originating from the exploding } \\
\text { device (preformed and natural (unformed) casing fragments, and other } \\
\text { projectiles deliberately introduced into the device to enhance the fragment } \\
\text { threat); and secondary fragments, which are projectiles from the } \\
\text { environment (debris, vehicular metal, etc.). Depending on their mass, shape } \\
\text { and velocity, some of these fragments may be capable of penetrating the } \\
\text { skin while others may just cause injuries from their contact pressure at } \\
\text { impact. }\end{array}$ \\
\hline $\begin{array}{l}\text { Tertiary } \\
\text { Blast } \\
\text { Injuries }\end{array}$ & $\begin{array}{l}\text { Displacement of the body or part of the body by the blast overpressure, } \\
\text { causing acceleration/deceleration to the body or its parts, which may } \\
\text { subsequently strike hard objects causing typical blunt injury (translational } \\
\text { injury), avulsion (separation) of limbs, stripping of soft tissues, skin } \\
\text { speckling with explosive product residue and building structural collapse } \\
\text { with crush and blunt injuries, and crush syndrome development. }\end{array}$ \\
\hline $\begin{array}{l}\text { Quinary } \\
\text { Injuries }\end{array}$ & $\begin{array}{l}\text { Qlinical consequences of "post detonation environmental contaminants" } \\
\text { including bacteria (deliberate and commensal, with or without sepsis), } \\
\text { radiation (dirty bombs), tissue reactions to fuel, metals, etc. }\end{array}$ \\
\hline $\begin{array}{l}\text { Quaternary } \\
\text { Injuries }\end{array}$ & $\begin{array}{l}\text { Other "explosive products" effects - heat (radiant and convective), and } \\
\text { injury. Quaternary blast injuries are more likely to occur inside vehicles } \\
\text { and in enclosed spaces where hot gases and toxic detonation products could } \\
\text { be retained. }\end{array}$ \\
\hline
\end{tabular}

\subsection{Epidemiology and data review}

The depth and breadth of blast injury research and development needs require that funding priorities for the design of personnel protective equipment, physical security concepts, weapons, collateral damage methodologies and medical treatments be informed by epidemiological data. Although the US military is doing a better job of collecting epidemiological data in the current conflict than ever before, the data have been contained in separate databases that are difficult to access, interrogate or review in aggregate. In recognition of this problem, the Technical Support Working Group recently funded SimQuest LLC to integrate three major sources of epidemiological data from the Global War on Terror (GWOT) and develop the Surface Wound Mapping data analysis tool. The resulting "Warfighter Battle Damage Assessment" (WBDA) prototype tool demonstrates the capability for a searchable database of the injuries occurring in 
Operation Iraqi Freedom (Champion and Cashman [2]). However, for this tool to guide research associated with blast injuries, additional work is required, including: (1) Further population of the database beyond the few hundred entries populated for the prototype development of the WBDA; (2) Advancements to account for anatomical variations; and (3) Integration with forensics data. With continued development, the databases and the Surface Wound Mapping tool together will not only allow for interrogation of epidemiological data, but also correlation of that data with forensics data regarding associated environment, insults and protective equipment.

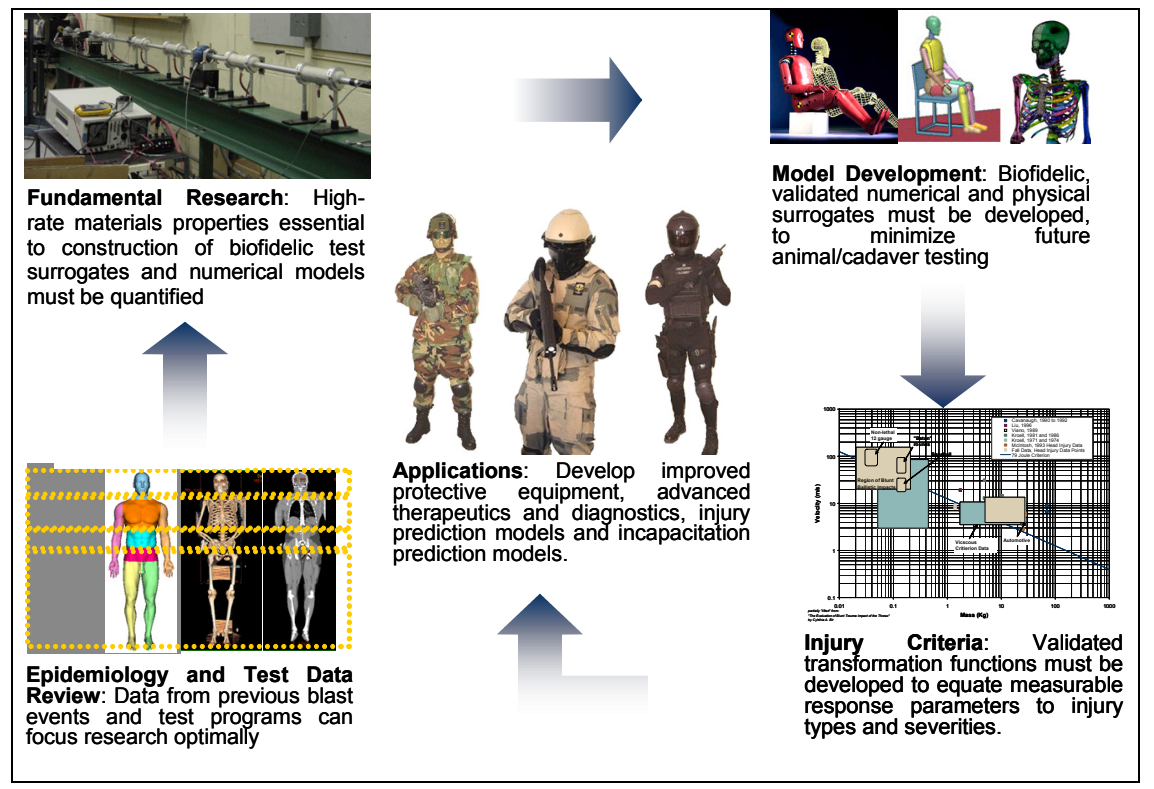

Figure 1: Blast injury research needs.

\subsection{Fundamental research}

At this time, there are two primary areas of basic research that must be accomplished to advance our capability to predict, prevent and treat blast injuries: (1) Understanding of the critical injury mechanisms and (2) Development of high-rate material properties for human tissue. Each of these is discussed below.

\subsubsection{Investigation of injury mechanisms}

The mechanism of injury for most explosion effects is well understood. The mechanism of injury, for example, when a fragment penetrates through tissue is known. Similarly, the mechanism of injury when a shock wave impinges on the eardrum is well-defined, and the mechanism of injury when it impinges on the 
lung tissue has benefited from over forty years of research. There are two major areas where continued research into injury mechanisms is required: blast Traumatic Brain Injuries (bTBI) and Synergistic/systemic Effects.

Blast Traumatic Brain Injuries. Recently, there has been compelling evidence that large numbers of previously unrecognized traumatic brain injuries may be occurring in military personnel exposed to improvised explosive device (IED) blasts in Iraq and Afghanistan (Ecklund [3], Warden [4]). The etiology and detailed progression of such brain injuries remains unknown, though the clinical spectrum may include a tendency to develop brain swelling or edema and diffuse vasospasm in the more severely injured patient population, and neurological deficits, sleep disturbances and other sequelae in the mildly injured patient population (Warden [4]).

Synergistic and Systemic Effects. Explosions rarely cause just one single wound or type of wound. Since the late 1960's, when blast injury research was first being aggressively pursued, the approach to dealing with the complexity of explosion effects has been to de-couple fragmentation effects from all others, and to make only superficial attempts to differentiate among the other blast effects.

\subsubsection{Constitutive material properties for human tissue}

Validated high-rate material properties for in vivo tissues are a prerequisite to developing biomechanical physical and numerical models of humans. The constitutive models of human tissue must include tissue failure at multiple rates. These properties can be obtained with animal and cadaver tissues using standard dynamic loading materials science tools such as the split Hopkinson bar.

\subsection{Model development}

Numerical, engineering and physical models must be developed to support blast injury research. Once validated, these models can be used to minimize the need for animal or cadaver testing, and they offer a means to perform stochastic analyses and sensitivity assessments. The major areas requiring development are:

1. Injury criteria and models to predict the type and severity of explosion injuries, and

2. Numerical models to provide a high-fidelity means of investigating blast/tissue interactions.

Capabilities and shortfalls pertaining to each of these types of models are summarized in the following paragraphs.

\subsubsection{Injury criteria and models}

The analysis of human lethality requires the application of appropriate data analysis techniques. An injury criterion is a "transformation function" which equates a measurable environmental condition or surrogate response to injury. In some cases, injury criteria will yield a binomial response: injury versus no injury, or no injury versus death. But, in most cases, injury criteria define a parameter space spanning from no injury through fatality (fig. 2). 
Table 2 summarizes some of the commonly used analysis methods and injury metrics applied in the blast environment. These criteria serve as metrics for evaluating the effectiveness of personal protection equipment and are used to define injuries in injury prediction models. The shortfalls associated with currently available injury criteria fall into a number of categories: (1) correlation to human injury severity metrics as a function of time, (2) validation and (3) applicability of persons in a variety of clothing and protection conditions.

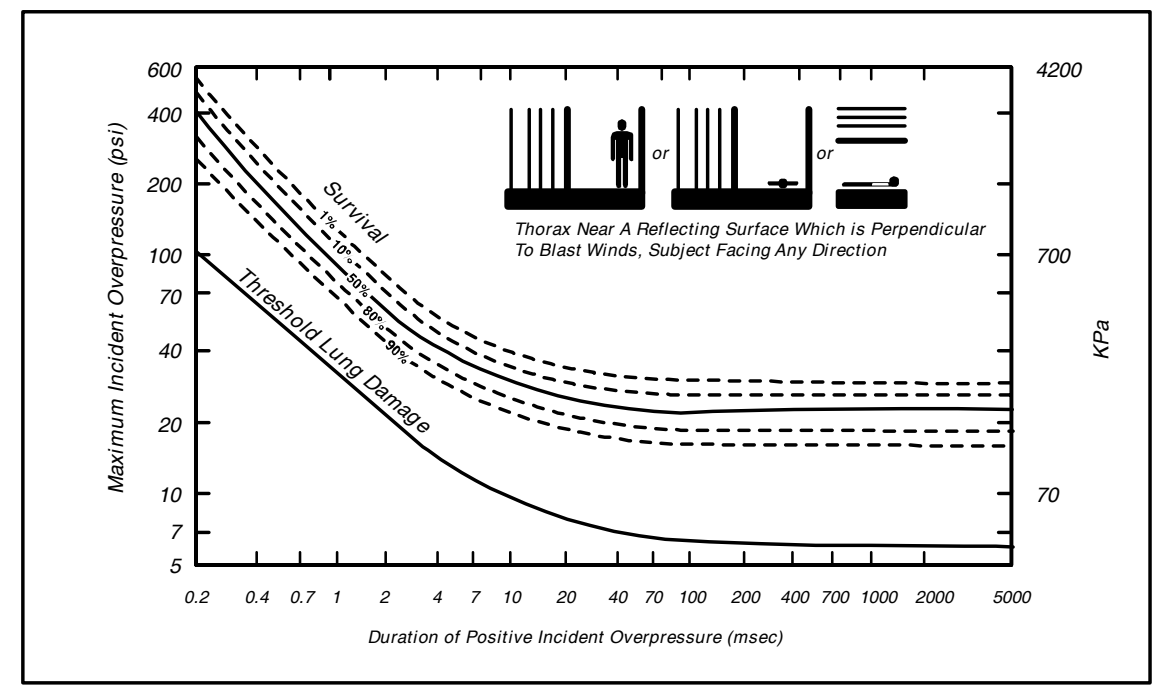

Figure 2: $\quad$ Bowen survival curves predicted for 70-kg man (Bowen et al [5]).

3.4.2.1 Human injury severity metrics To be transportable to other experimental models or to the field, injury criteria must be correlated to a common injury severity metric. Human effects injury severity scales such as the Abbreviated Injury Scale (AIS) [14], have been developed over the past thirty years with increasing refinement but there has been no focus on blast overpressure. In addition, when the injuries are multi-etiology, and only some of the etiologies have been quantified using the AIS system, quantifying the overall severity of injury is not possible.

3.4.2.2 Validation Injury criteria and human surrogates go hand-in-hand, because an injury criteria has no meaning unless it is defined relative to some measurable parameter. Thus, the discussion regarding validation of human surrogates is equally pertinent to a discussion regarding injury criteria validation. Considerable time and money have been devoted to validation of injury criteria and surrogates for the automobile safety community. A similar investment is needed for the blast injury community. 
Table 2: $\quad$ Summary of injury criteria and models.

\begin{tabular}{|c|c|}
\hline $\begin{array}{l}\text { Type of } \\
\text { Injury }\end{array}$ & Injury Criteria / Models \\
\hline Primary & $\begin{array}{l}\text { Primary blast injuries to the ear are typically analyzed using 1960's vintage } \\
\text { ear drum rupture curves (Ross et al [6]) or the Auditory Hazard Assessment } \\
\text { Algorithm For Human (Price [7]) model developed by the US Army } \\
\text { Research Laboratory. } \\
\text { Primary blast injuries to the lungs are analyzed using 1960's vintage } \\
\text { Bowen Curves (Bowen et al [5]), which are only applicable in an ideal } \\
\text { blast environment, the British Cumulative Sum Criterion (Cooper } \text { et al [8]) } \\
\text { or the US Normalized Work model (Stuhmiller et al [9]). This last model is } \\
\text { well-validated in a complex blast environment, but none of these models } \\
\text { are applicable for personnel wearing protective gear. } \\
\text { Injury criteria and models for primary blast injuries to the brain do not } \\
\text { exist. }\end{array}$ \\
\hline Secondary & $\begin{array}{l}\text { Penetrating metal fragments are typically assessed in the US using the } \\
\text { ORCA/ComputerMan (Gray et al [10]) model developed by the US Army } \\
\text { Research Laboratory. The Multi-Hit Glass Penetration (Young et al [11]) } \\
\text { handles penetration by glass fragments, not injury criteria or models } \\
\text { address penetrating structural debris. } \\
\text { The automobile safety and non-lethal weapons communities have a } \\
\text { number of blunt impact injury criteria. Most of these require substantial } \\
\text { validation or modification to be applicable for the rates of loading typical in } \\
\text { a blast environment. }\end{array}$ \\
\hline Tertiary & $\begin{array}{l}\text { Existing automotive safety injury criteria are applicable to tertiary blast } \\
\text { injuries, although these criteria assume specific directions of loading that } \\
\text { may or may not be representative in an actual blast event. In the event of a } \\
\text { collapsed structure, crush injuries are typically assumed fatal; therefore, a } \\
\text { crush model does not exist. }\end{array}$ \\
\hline $\begin{array}{l}\text { Quaternary } \\
\text { Blast } \\
\text { Injuries }\end{array}$ & $\begin{array}{l}\text { Thermal loads are typically analyzed using BURNSim (Knox et al [12]), a } \\
\text { US Army Research Laboratory model. This model is well-validated, but for } \\
\text { longer duration exposures than are typical in a blast environment. } \\
\text { Toxic gas injuries are assessed using TGAS (Leggeri [13]). TGAS } \\
\text { provides an estimate of the probability of incapacitation and lethality from } \\
\text { any combination of seven common fire gases (carbon monoxide, hydrogen } \\
\text { cyanide, hydrogen chloride, acrolein, nitrogen dioxide, low oxygen and } \\
\text { carbon dioxide) and } 21 \text { metabolized gases. }\end{array}$ \\
\hline Quinary & Appropriate models do not exist. \\
\hline
\end{tabular}

3.4.2.3 Applicability to clothing Finally, it is critical that the injury criteria be applicable to persons dressed in everyday clothing, military uniforms and personnel protection equipment. Existing criteria are almost entirely defined as "skin-inward" criteria, with only minimal research available into the effects of clothing. For many injuries, clothing effects will be minimal; however, personnel protective equipment will substantially modify the response of the human body to most explosion-induced insults. 


\subsubsection{Numerical models}

There are currently no validated blast bio-effects numerical models. Hydrocodes such as LS-DYNA [15] have been used throughout the counter-terrorism community to simulate the response of the body to blast. Unfortunately, none of the numerical models are validated and all share significant shortfalls:

Material Properties. The material properties currently used to characterize biological tissue are based upon low-rate loading. Because blast injuries are typically high-rate events, numerical models characterizing the biological response of tissue to blast cannot be validated until high rate material properties have been determined for major tissues such as bone, muscles, major organs, ligaments and tendons.

Anatomical Precision. Some blast effects on biological tissue cannot be captured without anatomically accurate modelling at the cellular level. Currently, most numerical models of the tissue are relatively coarse, going down to major blood vessels and nerves, but with limited modelling of smaller structures.

Multi-System Interactions. Existing numerical models typically capture just one anatomical region or biological system (e.g. nervous, cardiovascular, etc.). However, to accurately model the effects of blast on the body, its necessary to model most, if not all, of the body and the interactions between the various systems. For blast injuries, in particular, it is critical that respiratory, neurological and cardiovascular systems be modelled such that the effects of changes in the performance of one system can be seen in the other systems.

\section{Summary}

The preceding paragraphs highlight in some detail capabilities and shortfalls in the broad areas of epidemiological data, injury criteria and modelling. From this list of capabilities and shortfalls arises the following list of critical areas where research is required:

1. Epidemiology of penetrating trauma, high rate blunt trauma, high rate blast trauma and multi-system multi-etiology trauma.

2. Constitutive material properties to failure for high strain rate human tissue response.

3. Blast traumatic brain injury and synergistic injury mechanisms.

4. Validated injury criteria, engineering models and numerical models that would minimize the need to use biological surrogates when assessing equipment.

The capacity to predict the bio-effects of blast is required to adequately predict, prevent, mitigate and treat the effects of IED attacks. Major areas requiring research include Epidemiological Data, Validated Injury Criteria, and Physical, Engineering and Numerical Models. Funding of epidemiological data is ongoing and anticipated over the next several years. Major shortfalls remain in the areas of injury criteria and model development. Until these shortfalls are addressed, blast mitigation strategies will continue to be proposed and, frequently, implemented without a clear understanding of their ability to reduce loss of life or disabilities. 


\section{References}

[1] Young, LA, Champion, H.R. \& Bass, C.R., "Bioengineering of Blast Injury" prepared for Combating Terrorism Technology Support Office, under Contract F08637-03-C-6006, 2006.

[2] Champion, H.R. \& Cashman, P., "Next Generation Body Armor," Final Report to Combating Terrorism Technology Support Office, 2006.

[3] Ecklund, J., Personal communication, Chief of Neurosurgery, Walter Reed Army Medical Centre, Washington, DC, USA, February 15, 2006.

[4] Warden, D., Unpublished and untitled presentation based upon Defence Veterans Brain Injury Centre patient data, Walter Reed Army medical Center, Washington, DC, USA, October 10, 2005.

[5] Bowen, I.G., Fletcher, E.R. \& Richmond, D.R., "Estimate of Man's Tolerance to the Direct Effects of Airblast," prepared by Lovelace Foundation for Medical Education and Research for the Defense Atomic Support Agency, DASA-2113, 1968.

[6] Ross, R., et al., "Criteria for Assessing Hearing Damage Risk from Impulse-Noise Exposure," Human Engineering Laboratory, Aberdeen Proving Ground, MD, AD 666-206, 1967.

[7] Price, G.R. "A New Method for Rating Hazard from Intense Sounds: Implications for Hearing Protection, Speech Intelligibility, and Situation Awareness. In New Directions for Improving Audio Effectiveness," pp. KN2-1 - KN2-24. Meeting Proceedings RTO-MP-HFM-123, Keynote 2. Neuilly-sur-Seine, France: RTO, 2005.

[8] Cooper, G., Towsend, D.J., Carter, S.R. \& Pearce, B.P., "The Role of Stress Waves in Thoracic Visceral Injury from Blast Loading: Modification of Stress Transmission by Foams and High-Density Materials," Journal of Biomechanics, Volume 24, No. 5, pp. 273-285, 1991.

[9] Stuhmiller, J.H., Ho, K.H.-H., Vander Vorst, M.J., Dodd, K.T., Fitzpatrick, T. \& Mayorga M., "A Model of Blast Overpressure Injury to the Lung," Journal of Biomechanics, Volume 29, No. 2, pp. 227-234, 1996.

[10] Gray, J., Killion, E.M. \& Streit, B.K., "User's Manual for Operational Requirements-based Casualty Assessment (ORCA)," Prepared by Applied Research Associates, Inc., for the U.S. Army CBDCOM, 1997.

[11] Young, L.A., Stevens, D.J., Meyer, S.B., Becvar, K.E., Hayda, R., Bass, C.R., Kersul, A. \& Sunshine, C., "Glass Shard Flyout and Penetration Model," 11th ISIEM Conference Proceedings, Mannheim, Germany, 2003.

[12] Knox, F.S. III, Bonetti, D. \& Perry, C., "User's Manual for BRNSIM/BURNSIM: A Burn Hazard Assessment Model," USAARL Report No. 93-13, 1993.

[13] Leggeri, M., "T-Gas Release Notes," prepared by the Medical Research and Materiel Command, 2007. 
528 Safety and Security Engineering II

[14] Association for the Advancement of Automotive Medicine, Committee on Injury Scaling. The Abbreviated Injury Scale-1990 Revision (AIS-90). Des Plains, IL: Association for the Advancement of Automotive Medicine, 1990.

[15] "LS-DYNA Theoretical Manual," Livermore Software Technology Corporation, 1998. 